\title{
Intracranial Atherosclerosis: The Natural History and Management Strategies
}

\author{
Ossama Mansour1,2, Martin Schumacher', Mohammad A. Farrag3, Foad Abd-Allah ${ }^{3}$ \\ ${ }^{1}$ Neurology and Interventional Neurology Service Department, Alexandria University Hospital, Alexandria, \\ Egypt \\ ${ }^{2}$ Freiburg Uniklinik, Neurozentrium, Neuroradiologie Abt., Freiburg, Germany \\ ${ }^{3}$ Neurology Department, Cairo University Hospitals, Cairo, Egypt \\ Email: foad.abdallah@kasralainy.edu.eg.
}

Received 20 April 2014; revised 23 May 2014; accepted 31 May 2014

Copyright (C) 2014 by authors and Scientific Research Publishing Inc.

This work is licensed under the Creative Commons Attribution International License (CC BY).

http://creativecommons.org/licenses/by/4.0/

(c) (i) Open Access

\begin{abstract}
Intracranial atherosclerotic disease (ICAD) represents a major cause of stroke and transient ischemic attacks. The prevalence and natural course of ICAD are closely related to race and ethnicity. The best treatment for ICAD is a crucial issue; data from recent trials indicate that aggressive medical management and life style modifications are better than endovascular treatments for prevention of recurrent stroke in high-risk patients with ICAD. Endovascular treatment is still an option for subgroup of patients who are not responded to optimal medical therapy.
\end{abstract}

\section{Keywords}

Intracranial Atherosclerosis, Medical Therapy, Endovascular Treatment

\section{Introduction}

Stroke is one of the global leading causes of death and disability as confirmed by many epidemiological studies [1]. Intracranial cerebral atherosclerosis accounts for approximately $8 \%-10 \%$ of all ischemic strokes with a higher reported incidence in the Asian, African, and Hispanic descent populations [2]. Ethnicity accounts for significant variation in the incidence of the disease in symptomatic patients, but the effect of ethnicity in asymptomatic patients is not clear [3].

The risk factors for the development of intracranial atherosclerotic disease are broadly classified as non-modifiable (e.g. age, gender); modifiable-which are well documented-(e.g. hypertension, total serum cholesterol); and potentially modifiable factors—which are less well documented-(e.g. diabetes mellitus, metabolic syndrome) [4].

\footnotetext{
*Corresponding author.
} 
Patients with intracranial atherosclerosis are classed as symptomatic or asymptomatic. The annual stroke risk in patients with intracranial atherosclerosis is estimated to be 3.6\% - 13\% annually, with a first year ischemic stroke rate in the pertinent vascular territory of at least $11 \%$ [5]. Patients who experience a stroke or transient ischaemic attack due to a stenosis of 50\% - 99\% have traditionally been treated with antithrombotic medication. Even with this treatment there remains a $12 \%$ - 14\% risk of further stroke in the subsequent 2 years, increasing to $20 \%$ in at-risk individuals [4]. Trials comparing antithrombotic medications with anticoagulants for prevention of stroke or vascular events have not generated satisfactory results and, worse still, have been associated with high rates of bleeding [5].

Intracranial angioplasty (with or without a stent) was developed as a treatment option for patients with symptomatic intracranial atherosclerotic disease. Early intracranial angioplasty techniques used balloons, followed by balloon-mounted intracranial stents [6], but this was associated with high technical failure rates. In 2005, the Wingspan $^{\mathrm{TM}}$ stent system with Gateway ${ }^{\mathrm{TM}}$ percutaneous transluminal angioplasty balloon was approved by the US Food and Drug Administration for the treatment of intracranial atherosclerotic disease with $>50 \%$ stenosis [7].

Intracranial stent-assisted intervention is associated with several complications, including the formation of blood clots, thromboembolism, vascular rupture, dissection and re-narrowing in the long-term [8]. The reported risk of stroke and death during the procedure itself varies between $0 \%$ and $30 \%$. These complications risk prompted this systematic review of the available literature to determine the effectiveness of intracranial angioplasty with stenting for treatment of intracranial atherosclerosis.

\section{Intracranial Atherosclerotic Disease (ICAD)}

\subsection{Natural Course and Clinical Prognosis}

The natural history of stenosis secondary to intracranial atherosclerosis has been angiographically studied by Akins et al. [9]. Over a follow-up period of more than 2 years, they found an increase in the degree of stenosis in the MCA-ACA-PCA group, whereas intracranial ICA stenoses remained stable with a 14\% regression in intracranial ICA stenosis and a 28\% regression in the MCA-ACA-PCA group. Accordingly, they concluded that intracranial lesions are dynamic and may progress or regress with time.

Many studies were conducted [10] [11] evaluating the effect of cilostazol and clopidogrel in intracranial atherosclerosis, a total of $14 \%$ of patients demonstrated lesion progression. The risk of future ischemic strokes depends on whether the vessel is asymptomatic or symptomatic. This difference has been well studied in the WASID trial (Warfarin vs. Aspirin for Symptomatic Intracranial Disease) [5], where patients recruited in the trial, though symptomatic, also had asymptomatic stenoses in other arteries. When these patients were followed up, the 1-year risk of developing a stroke in the territory of these asymptomatic vessels was 3.5\% (CI 0.8\% - 9\%). In contrast to this, patients with $\geq 70 \%$ stenosis had a risk of $14 \%$ at one year for a stroke in the same territory and $19 \%$ for stroke in any vascular territory.

Apart from severity of stenosis, recent symptoms and female gender also predicted risk of stroke recurrence in this study [12]. A similar risk rate of 14\% was reported from the GESICA (Grouped’ Etude des Sténoses IntraCrâniennes Athéromateusessymptomatiques) study [13]. A WASID sub study [14] has identified that the presence of collaterals is a strong predictor of subsequent stroke in case of moderate-to-severe stenosis, but milder stenoses are more unstable.

\subsection{Pathophysiology, Clinical and Radiological Presentation of ICAD}

\subsubsection{Intracranial Arterial Steno-Occlusion}

Intracranial atherosclerotic disease could be asymptomatic or presents with ischemic strokes and transient ischaemic attacks (TIA). Several proposed mechanisms could be behind this ischemia which includes artery-toartery embolism, local branch occlusion, hemodynamic compromise resulting from progressive arterial narrowing, or a combination of these factors [15]. The radiological presentations of these strokes include cortical infarctions, watershed infarctions [16] and lacunes [17].

Progressive reduction in flow due to progressive narrowing of the large atherosclerotic arteries leads to gradual formation of leptomeningeal collaterals. When the compromise reaches a stage when these collaterals are insufficient to maintain perfusion to the terminal areas, infarctions develop in border zone territories [18]. Both internal and cortical border zone infarctions of the MCA territory are reported in literature to result from ICAD [19]. 
Reduction of regional cerebral blood flow is identified in the presence of high-grade stenosis and contributes both to the occurrence and magnitude of ischaemic injury [20].

Lacunar infarctions identified in $10 \%-19 \%$ of patients are most often located in the pons followed by the corona radiata or centrum semiovale regions [21].

Clinical presentation includes cortical function impairments such as aphasia, neglect, and hemianopsia in almost half of patients with cortical and large subcortical infarctions. In the remaining patients, signs of isolated motor or sensory deficits predominate, in association with lacunar and small subcortical infarctions [22].

\subsubsection{Intracranial Arterial Dolichoectasia (IADE): The Hidden Convict}

Symptomatic intracranial atherosclerosis, not only could cause stroke via different mechanisms related to the steno-occlusive pathology but it could be associated with stroke related to intracranial arterial dolichoectasia (IADE); the other ICAD fingerprint as well. Approximately one patient in eight who has brain imaging has some increase in the length and diameter of intracranial arteries [23].

IADE has been found in $12 \%$ of stroke patients [24]. IADE may be asymptomatic, or it may be associated with clinical manifestations such as stroke, subarachnoid hemorrhage, cranial nerve palsy, compression of the midbrain, or obstructive hydrocephalus [25].

Regarding IADE haemodynamic changes; the process of marked elongation, widening, and tortuosity of arteries is termed dilatativearteriopathywhere intracranial vertebral and basilar arteries are preferentially affected. This type of angiopathy is characterized by an abnormally enlargement of the external diameter and thinning of the arterial wall, with degeneration of the internal elastic lamina leading to multiple gaps in the internal elastica, and thinning of the media secondary to reticular fiber deficiency, and smooth muscle atrophy [26].

Bidirectional flow changes in dilated arteries can reduce the antegrade flow and can results in thrombus formation. Additionally, elongation and angulations of arteries can impair blood flow especially in the penetrating branches due to stretching and distortion of the orifices of the arterial branches [26].

The prognosis for patients with dolichoectasia is highly variable, ranging from benign to malignant. In one study, dolichoectasia progressed in $43 \%$ of patients, and occurred more frequently in younger patients and those with anterior circulation involvement. Overall, there is a high frequency of recurrent events. One study of 93 patients over 11 years found that $60 \%$ had at least one clinical event, of which ischemic strokes comprised $80 \%$ [26].

\subsection{Counting the Facts for ICAD Management from Reviewing of Current Studies}

\subsubsection{Review of Medical Therapy}

1) Medical treatment for intracranial arterial steno-occlussion

Patients with symptomatic intracranial large artery stenosis $>50 \%$ treated either with aspirin or warfarin were evaluated for success of medical therapy in the first WASID trial in a retrospective manner [5]. Where during a mean follow-up of 14.7 months in the warfarin-treated group, there was an $8.4 \%$ stroke or death rate, and in the aspirin treated group there was an $18.1 \%$ rate of major stroke or death, with $9 \%$ stroke in the same vascular territory.

Based upon these data, a second pivotal trial was subsequently performed. The multi-center, randomized, double-blind NIH-sponsored WASID trial was performed from 1998-2003 where the trial was prematurely halted due to concerns about the safety of the patients who had been assigned to receive warfarin [5].

In this trial because of the higher adverse event rates (stroke and death), higher symptomatic hemorrhage rate for patients treated with warfarin, and lack of therapeutic benefit of warfarin over aspirin for prevention of ischemic stroke secondary to intracranial stenosis, it was concluded that aspirin should be used in preference to warfarin for patients with intracranial arterial stenosis. However, the most important message was neither therapy offered acceptable protection from stroke.

The WASID authors concluded that "these data indicate that intracranial stenosis is a high-risk disease for which alternative therapies are needed" [5].

After results of the SAMPRIS trial; the aggressive medical therapy (AMT) is considered as the first choice, beside life style modifications, for treatment of symptomatic ICAD. The trial adopted the following strategy, Aggressive medical treatment consisted of aspirin $325 \mathrm{mg}$ daily plus clopidogrel $75 \mathrm{mg}$ daily for 90 days, intensive management of vascular risk factors (primarily targeting systolic blood pressure $<140 \mathrm{mmHg}$ and $<130$ $\mathrm{mmHg}$ if diabetic, as well as LDL ( $<70 \mathrm{mg} / \mathrm{dl})$, and provision of a lifestyle modification program [58]. 
2) Medical treatment for intracranial arterial dolichoectasia (IADE)

Treatment of dolichoectasia remains uncertain. Antiplatelet or anticoagulant treatments have limited effectiveness, perhaps due to multiple stroke mechanisms other than atherosclerosis. In one prospective study, patients who initially presented with ischemia or other symptoms due to vertebrobasilar dolichoectasia and who were treated with antiplatelets or anticoagulants had a higher incidence of hemorrhage [27]. Further study is needed to assess the risks and benefits of antiplatelet or anticoagulation treatment for vertebrobasilar dolichoectasia. Caution is advised in giving antiplatelets or anticoagulants to vertebrobasilar dolichoectasia patients who present with symptoms other than ischemia (e.g., hemifacial spasm or cranial nerve deficits).

\subsubsection{Intracranial Angioplasty and Stenting (Endovascular Treatment of ICAD)}

1) Primary Intracranial Angioplasty

The earliest reports of angioplasty for intracranial atherosclerosis using coronary balloon were reported, a large number of individual series of cases were consequently published in literature with technical success rates exceeding 90\%, with clinical complication rates ranging from 0\% - 20\% [28]-[32].

Sundt et al. [33] first reported angioplasty for treatment of symptomatic intracranial stenosis. Early studies reported a 33\% complication rate in the form of intraprocedural vessel rapture, vasospasm, dissection or death [34]. Subsequent studies have reported less than $50 \%$ residual stenosis with few complication rates in retrospective case series [35].

Marks et al. reported 23 patients with symptomatic ICAD treated by Percutaneous Transluminal Angioplasty (PTA) which resulted in reduced stenosis in 21 of 23 patients. In one patient crossing of the lesion failed and the other patient died as a result of vessel rupture from ballondilation. Three years follow-up after the procedures showed annual stroke rate of 3.2\% [35].

Conners and Wojak reported overall good angiographic and clinical outcomes in $98 \%$ of transluminal angioplasty procedures performed upon 70 patients with ICAD along a period of 9 years [36].

Callahan and Berger conducted a study on 15 patients with ICAD related stroke who had failed warfarin therapy. Dilation was successful in all vessels with residual stenosis averaging $<30 \%$ however, one patient died secondary to vessel rupture and another patient suffered pontinestroke secondary to perforator compromise and another diedfrom ICH after perforation by the guidewire [34].

Nahser et al. reported 20 patients with vertebrobasilar stenosis treated with PTA with success rate was 86\%.One patient had an ischemic stroke during the procedure [37]. Within 3 - 18 months follow-up a 14\% rate of restenosis was encountered.

Marks et al. reported retrospectively on their experience of treating a cohort of patients all had neurological symptoms on medical therapy with 37 symptomatic atherosclerotic intracranial stenotic lesions by PTA [38]. They achieved a decline in the mean stenosis from $84.2 \%$ to $43.3 \%$ after treatment with periprocedural stroke and death rate $8.3 \%$. The annual stroke rate in the territory of the treated lesion was $3.4 \%$ and in the subset of patients with $>50 \%$ residual stenosis, it was $4.5 \%$.

The long-term clinical benefit of endovascular therapy for intracranial atherosclerosis is studied by Wojak et al. [36]. The authors performed Angioplasty alone in 62 procedures, while 22 procedures involved intracranial stenting with overall complication-free procedural success rate of $90.5 \%$. The periprocedural stroke or death rate was $4.8 \%$. Angiographic restenosis occurred in 23 lesions at a mean of 4.6 months; 13 were re-treated without complication. The annualized stroke rate in the treated vascular territory was $1.8 \%$, and the annualized stroke and death rate was $3.0 \%$.

Feasibility of the procedure was confirmed in many in the above mentioned descriptive studies though it carries a significant morbidity and mortality risk in the form of periprocedural complications such as vessel occlusion, immediate elastic recoil, dissection of the artery, and higher restenosis rates.

Additionally, extrapolating the vast amount of data from the coronary literature has rendered balloon angioplasty alone may be inferior compared to angioplasty with stenting. However, that being said the two modalities have not been compared head to head prospectively. Evidence could be extracted from randomized controlled trials assessing the safety and effectiveness of both procedures in preventing recurrent stroke.

2) Intracranial Angioplasty and Stent Placement

Three types of stents are available and already experienced in a lot of ICAD treatment trials; balloon expandable bare metal stents (BEBMS), drug-eluting balloon expandable stents, and self-expanding stents. From the technical point; these stentscould be divided into those primarily designed for the coronary vasculature or those that have 
been designed for intracranial one.

Frequent dissection complicating Primary angioplasty without stent placement was recorded in initial series [39]-[44]. However, many of the coronary BEBMS stents were rigid making them difficult to navigate into the intracranial circulation. They were the only available stents at that time to be used in an acute vessel dissection after angioplasty of an ICAD lesion [45].

For fairness, some of them were found to be flexible enough to track into the intracranial vasculature like; Gianturco-Rubin-2 stent [46], Palmaz-Schatz stent [45], and the Arterial Vascular Engineering stent series which included the AVE S670 stent and Guidant Tetra multilink stent. However, with highly flexible BEBMS, some difficulties of navigation could hinder the success achievement of the procedure like in series published by Mori et al. [47].

Yu et al. reported the outcomes of stenting for symptomatic basilar artery stenosis $(79.6 \% \pm 11.7 \%)$ over a 4-year period [48]. There were $11.1 \%$ neurological complications but no deaths. At a mean follow-up of 26.7 months, $83.3 \%$ had excellent long-term functional outcome with $55.6 \%$ being asymptomatic, although $27.8 \%$ experienced several minor episodic symptoms without disability.

Gomez et al. reported near similar results upon 12 patients undergoing elective stenting for symptomatic basilar artery stenosis, with a $100 \%$ technical success [49].

Mazighi et al. treated 69 intracranial arterial lesions with coronary BEMBS [50] in retrospectively reexamined 53 consecutive symptomatic patients. A success rate of $98.6 \%$ was achieved, with a reduction of the median percent stenosis from 85 to $0 \%$. Stents were used in $76.8 \%$. Death or stroke rate was $10.1 \%$ with one death during theperiod of follow-up of 30 days.

In SSYLVIA study (The stenting of symptomatic atherosclerotic lesion in the vertebral or intracranial arteries) the NEUROLINK System (Guidant Corporation)—specifically designed for navigating intracranial vasculature —was used in forty-three patients with intracranial arteries and 18 patients with extracranial vertebral arteries. 6.6\% was the rate of occurrence of ischemic strokes while no deaths during the first 30 days follow up. While after 30 days, $7.3 \%$ of patients had recurrent strokes [51].

The NEUROLINK system was not marketed even past the trial. However, this trial provided valuable data about the safety of stenting in the treatment of ICAD. Since The NEUROLINK system discontinuation until very recently there were no other BEBMS for ICAD. However, most recently, Micrus Corporation ${ }^{\circledR}$ (San Jose, CA, USA) has designed the Pharos Vitesse Chrome Cobalt BEMS that is under study in Europe [52].

3) Drug-Eluting Stents (DES)

DES is designed to have a coating of antiproliferative drug that inhibits neointimal hyperplasia like in the coronary vasculature some centers have employed its use to treat ICAD. Pacilitaxel-coated stents were used to treat series of cases with symptomatic posterior circulation stenosis with $7.7 \%$ periprocedural stroke. The study reported 69.2\% free in-stent stenosis during a mean period of follow up of about 6 months [53]. Qureshi et al. by using DES in treating series of symptomatic ICAD patients ( $\geq 70 \%$ or failed medical management), he achieved a major stroke-free survival of $86 \%$, with only $5.5 \%$ symptomatic angiographic restenosis during the follow-up period of 12 months [54]. Similarly Abou-Chebl et al. [55] and Gupta et al. [56] showed feasibility and safety by treating symptomatic lesions with DES with lesser in-stent restenosis during the period of follow-up. The previous DES studies used first generation stents with sirolimus or paclitaxel.

While recently Natarajan et al. reported their experience in treating symptomatic ICAD using a second generation DES that has greater deliverability [57]. In this study, The Xience V everolimus-eluting stent (Abbott Vascular) was placed in six patients with $>70 \%$ stenosis with average stenosis reduction from $83 \%$ to $6 \%$, one periprocedural ICH (Intracerebral haemorrahge) was reported and $83.3 \%$ of the cases followed up for about 6 months without in-stent restenosis.

More studies are required to confirm the safety and effectiveness of DES in the intracranial vasculature. The ongoing concerns with DES are the need for prolonged use of dual antiplatelet therapy with aspirin and clopidrogel which may increase the risk of hemorrhage especially in the brain and late restenosis.

4) Self-Expanding Intracranial Stents

The year of 2011 was disappointing forneuro-interventionists interested in cerebral revascularization to prevent stroke from intracranial atherosclerotic steno-occlusive disease. Specially after the results of the Stenting and Aggressive Medical Therapy for Preventing Recurrent Stroke in Intracranial Stenosis (SAMMPRIS) study [58].

High recurrent stroke risks in patients with symptomatic intracranial stenosis were the driving force for device 
development for treatment [59]. Wingspan (Boston Scientific, Natick, MSA, USA), a self-expandable stent, was developed for this purpose with improved flexibility and trackability with a reasonable safety profile [60] [61].

SAMMPRIS was an investigator-initiated randomized, controlled, blindly adjudicated multi-center clinical trial to test whether early angioplasty and stenting can reduce subsequent ischemic stroke risk in patients with symptomatic severe stenosis of a major intracranial artery.

Aggressive medical management in both arms consisted of aspirin $325 \mathrm{mg}$ daily for the entire follow-up, clopidogrel $75 \mathrm{mg}$ daily for 90 days, intensive management of vascular risk factors (primarily targeting systolic blood pressure $<140 \mathrm{mmHg}$ and $<130 \mathrm{mmHg}$ if diabetic, as well as $\mathrm{LDL}<70 \mathrm{mg} / \mathrm{dl}$ ), and provision of a lifestyle modification program.

The target sample size was 372. Enrolment within 30 days of symptoms was intended to maximize possible stroke reduction during the high-stroke-risk period. SAMMPRIS recruitment was halted in April 2011 by the United States National Institute of Neurological Disorders and Stroke (NINDS) for the significantly higher 30-day rate of stroke or death in the stenting arm as compared to the aggressive medical management alone arm ( $14 \%$ vs. 6\%) [62] [63].

The 30-day rate of stroke or death in the aggressive medical management alone arm was lower than historical controls, while the 30-day rate of stroke or death in the stenting arm was higher than previous registry data [34]. The subsequent stroke risks were similar at last follow-up [63]. Higher 30-day rate of stroke or death in the stenting arm was thought to be related technical aspects of the Wingspan stent system (WS System) and lack of an angioplasty with stent placement, in addition, the inappropriate selection of patients, may have led to early termination of the study. Future randomized trials with different devices and modified patient selection criteria are warranted. Another similar single-center trial is ongoing with a target sample size of 200 in Hong Kong [64].

\subsubsection{Surgical Revascularization-EC/IC Bypass Trial}

Researches into hemodynamic factors have shed light on the pathogenesis of the strokes caused by haemodynamicischaemia identified different stages of cerebral hemodynamic failure.

Stage I refers to autoregulatory vasodilatation which maintains a constant cerebral blood flow but with reduced responsiveness of cerebral blood flow to a vasodilatory stimulussuch as hypercapnia or acetazolamide. Stage II is indicated by increases in regional oxygen perfusion, which is also known as misery perfusion. Stage II hemodynamic failure correlates withmarkedly elevated stroke risk and formed the basis to further evaluate surgical revascularization in new randomized trials targetingthis patient subgroup [65]. The year 2011 carried more disappointing news for neurosurgeons who are interested in revascularization of steno-occlusive pathology. After the results of the COSS (Carotid Occlusion Surgery Study) [66], where Extracranial-intracranial (EC-IC) bypass for intracranial atherosclerotic steno-occlusive diseases and its indications have undergoneintense scrutiny and reevaluation after the negative results of the initial EC-IC Bypass Study published in the New England Journal of Medicine in 1985 [67]. Subsequent efforts have focused on identifying patients at high risk of subsequent stroke after carotid occlusion, withthe hypothesis that stroke risk reduction in patients with highstroke risk will outweigh the procedural risks of EC-IC bypass.

COSS was a randomized, controlled, blindly adjudicated multi-center clinical trial designed to determine whether surgical revascularization can reduce subsequent ischemic stroke in high-stroke-risk patients with symptomatic internal carotid artery occlusion (SICAO) with corresponding stage II cerebral hemodynamic failure. Surgical revascularization is achieved by anastomosis of the superficial temporal artery to the middle cerebral artery. Their target sample size was 372. The results were presented in February 2011 [42] [68]. COSS recruitment was stopped by the Data Safety Monitoring Board in June 2010 as the pre-defined boundary for declaring futility was crossed. One hundred ninety-five subjects were randomized.

Analysis of the 142 subjects who had been followed for two years confirmed that the two-year stroke recurrence rates were $21 \%$ and $23 \%$ for the surgical group and the medical therapy alone group respectively $(p=0.88$, logrank test).Graft patency rate at last follow-up was 96\% [68]. The lack of benefit is attributed to better stroke prevention in the medical group as compared to historical controls.

The COSS study with no doubt is definitely an important landmark study in cerebral revascularization. A pivotal question has been answered without the shadow of any bias the study has showed that in spite of hemodynamic improvement and excellent graft patency in patients treated with extracranial-intracranial arterial bypass, there was no benefit in reducing new stroke events when compared with the patients randomized to best medical treatment alone. However a number of questions need to be clarified for neurovascular specialists involved in 
the management of symptomatic internal carotid artery occlusion (SICAO).

1) What would be the best treatment option for patients who in spite of maximal medical treatment continue to have symptoms in the form of TIAs or recurrent strokes?

2) What is the underlying mechanism in patient with SICAO shows a clinical perfusion mismatch but continue having symptoms despite restoration of good hemodynamic status following bypass surgery.

3) The study does not address the issue of cognitive impairment either pre or postoperatively in patients with SICAO and whether medical treatment or bypass surgery had a differential impact on improvement or deterioration in patients with such impairment.

4) PET although a very elegant method of determining the cerebral metabolic rate by quantifying regional oxygen consumption, however, using the oxygen ligand for PET still remains expensive and impractical for use as a routine method of investigating patients with SICAO. Further studies need to identify more economical and practical method to stratify patient with SICAO.

\section{How the Reading of the Above Mentioned Studies Could Update the Current Position Statement Regarding Intracranial Stenting in ICAD}

1) The health care authorities should invest more in preventive strategy by aggressive medical control which of course needs more finances to change both physician and patient orientation.

2) The prevention strategies should involve life style modifications beside "best medical therapy" in patients with intracranial atherosclerotic steno-occlusive diseases.

3) For symptomatic patients with a $>50 \%$ intracranial stenosis who have failed medical therapy, balloon angioplasty with or without stenting should be considered.

4) Proper selection of patients suitable for surgery or neurointervention is with lower procedural risk. Patients with symptomatic steno-occlusive disease should be differentiated into subcategorical groups according to the pathological mechanisms:

a) Focal short segment atherosclerotic steno-occlusive disease benefits from balloon angioplasty and/or stenting, if best medical treatment fails.

b) Patients with perforator syndrome due to branch ostial stenosis harbor higher procedural stroke risk due to plaque shifting into the ostia of the perforators, completing the infarct, thus may derive minimal benefit in terms of future stroke risk reduction, in spite of restoration of flow to the asymptomatic distal territory.

c) Patients with carotid occlusion with persistent fluctuating symptoms and severe hemodynamic insufficiency should still be considered for the benefit of surgery.

5) Patients with asymptomatic intracranial arterial stenosis should first be counseled regarding the nature and extent of their disease, and then regarding optimizing medical therapy and the impact of controlling risk factors as in SAMPRIS-Fashion on the clinical outcome. They should be monitored for any neurological symptoms, and have periodic non-invasive imaging at regular intervals using transcranial Doppler, magnetic resonance angiography or computed tomographic angiography initially, and then by cerebral angiography if warranted. At a minimum, optimal prophylactic medical therapy should be instituted, which might include antiplatelet and/or statin therapy.

6) Continued evaluation and improvements in both pharmacological and catheter-based therapies, in parallel not competing manner are needed to reduce the stroke burden from intracranial atherosclerosis. Up till now, there is insufficient evidence to make definitive recommendations regarding endovascular therapy in asymptomatic patients with severe intracranial atherosclerosis.

\section{References}

[1] Taylor, T.N., Davis, P.H., Torner, J.C., Holmes, J., Meyer, J.W. and Jacobson, M.F. (1996) Lifetime Cost of Stroke in the United States. Stroke, 27, 1459-1466. http://stroke.ahajournals.org/content/27/9/1459

[2] Wityk, R.J., Lehman, D., Klag, M., Coresh, J., Ahn, H. and Litt, B. (1996) Race and Sex Differences in the Distribution of Cerebral Atherosclerosis. Stroke, 27, 1974-1980. http://stroke.ahajournals.org/content/27/11/1974

[3] White, H., Boden-Albala, B., Wang, C.L., Elkind, M.S.V., Rundek, T., Wright, C.B. and Sacco, R.L. (2005) Ischemic Stroke Subtype Incidence among Whites, Blacks, and Hispanics: The Northern Manhattan Study. Circulation, 111, 1327-1331. http://dx.doi.org/10.1161/01.CIR.0000157736.19739.D0 
[4] Qureshi, A.I., Feldmann, E., Gomez, C.R., Johnston, S.C., Kasner, S.E., Quick, D.C., Rasmussen, P.A., Fareed, M., Suri, K., Taylor, R.A. and Zaidat, O.O. (2009) Intracranial Atherosclerotic Disease: An Update. Annals of Neurology, 66, 730-738. http://dx.doi.org/10.1002/ana.21768

[5] Chimowitz, M.I., Lynn, M.J., Howlett-Smith, H., Stern, B.J., Hertzberg, V.S., Frankel, M.R., Levine, S.R., Chaturvedi, S., Kasner, S.E., Benesch, C.G., Sila, C.A., Jovin, T.G. and Romano, J.G. (2005) Comparison of Warfarin and Aspirin for Symptomatic Intracranial Arterial Stenosis. New England Journal of Medicine, 352, 1305-1316. http://dx.doi.org/10.1056/NEJMoa043033

[6] Siddiq, F., Memon, M.Z., Vazquez, G., Safdar, A. and Qureshi, A.I. (2009) Comparison between Primary Angioplasty and Stent Placement for Symptomatic Intracranial Atherosclerotic Disease: Meta-Analysis of Case Series. Neurosurgery, 65, 1024. http://dx.doi.org/10.1227/01.NEU.0000360138.54474.52

[7] Bose, A., Hartmann, M., Henkes, H., Liu, H.M., Teng, M.M.H., Szikora, I., Berlis, A., Reul, J., Yu, S.C.H., Forsting, M., Lui, M., Lim, W. and Sit, S.P. (2007) A Novel, Self-Expanding, Nitinol Stent in Medically Refractory Intracranial Atherosclerotic Stenoses. Stroke, 38, 1531-1537. http://dx.doi.org/10.1161/STROKEAHA.106.477711

[8] Eberhardt, O., Naegele, T., Raygrotzki, S., Weller, M. and Ernemann, U. (2006) Stenting of Vertebrobasilar Arteries in Symptomatic Atherosclerotic Disease and Acute Occlusion: Case Series and Review of the Literature. Journal of Vascular Surgery, 43, 1145-1154. http://dx.doi.org/10.1016/j.jvs.2006.02.027

[9] Akins, P.T., Pilgram, T.K., Cross III, DeWitte T. and Moran, C.J. (1998) Natural History of Stenosis from Intracranial Atherosclerosis by Serial Angiography. Stroke, 29, 433-438. http://dx.doi.org/10.1161/01.STR.29.2.433

[10] Kwon, S.U., Cho, Y.-J., Koo, J.-S., Bae, H.-J., Lee, Y.-S., Hong, K.-S., Lee, J.H. and Kim, J.S. (2005) Cilostazol Prevents the Progression of the Symptomatic Intracranial Arterial Stenosis: The Multicenter Double-Blind Placebo-Controlled Trial of Cilostazol in Symptomatic Intracranial Arterial Stenosis. Stroke, 36, 782-786. http://dx.doi.org/10.1161/01.STR.0000157667.06542.b7

[11] Lee, Y.S., Bae, H.-J., Kang, D.-W., Lee, S.-H., Yu, K., Park, J.-M., Cho, Y.-J., Hong, K.-S., Kim, D.-E., Kwon, S.U., Lee, K.B., Rha, J.-H., Koo, J., Han, M.-G., Lee, S.J., Lee, J.-H., Jung, S.W., Lee, B.-C. and Kim, J.S. (2011) Cilostazol in Acute Ischemic Stroke Treatment (CAIST Trial): A Randomized Double-Blind Non-Inferiority Trial. Cerebrovascular Diseases, 32, 65-71. http://dx.doi.org/10.1159/000327036

[12] Kasner, S.E., Chimowitz, M.I., Lynn, M.J., Howlett-Smith, H., Stern, B.J., Hertzberg, V.S., Frankel, M.R., Levine, S.R., Chaturvedi, S., Benesch, C.G., Sila, C.A., Jovin, T.G., Romano, J.G. and Cloft, H.J. (2006) Predictors of Ischemic Stroke in the Territory of a Symptomatic Intracranial Arterial Stenosis. Circulation, 113, 555-563. http://dx.doi.org/10.1161/CIRCULATIONAHA.105.578229

[13] Mazighi, M., Tanasescu, R., Ducrocq, X., Vicaut, E., Bracard, S., Houdart, E. and Woimant, F. (2006) Prospective Study of Symptomatic Atherothrombotic Intracranial Stenoses. Neurology, 66, 1187-1191. http://dx.doi.org/10.1212/01.wnl.0000208404.94585.b2

[14] Liebeskind, D.S., Cotsonis, G.A., Saver, J.L., Lynn, M.J., Cloft, H.J. and Chimowitz, M.I. (2011) Collateral Circulation in Symptomatic Intracranial Atherosclerosis. Journal of Cerebral Blood Flow \& Metabolism, 31, 1293-1301. http://dx.doi.org/10.1038/jcbfm.2010.224

[15] Wong, K.S., Gao, S., Chan, Y.L., Hansberg, T., Lam, W.W.M., Droste, D.W., Kay, R. and Ringelstein, E.B. (2002) Mechanisms of Acute Cerebral Infarctions in Patients with Middle Cerebral Artery Stenosis: A Diffusion-Weighted Imaging and Microemboli Monitoring Study. Annals of Neurology, 52, 74-81. http://dx.doi.org/10.1002/ana.10250

[16] Del Sette, M., Eliasziw, M., Streifler, J.Y., Hachinski, V.C., Fox, A.J. and Barnett, H.J. (2000) Internal Borderzone Infarction: A Marker for Severe Stenosis in Patients with Symptomatic Internal Carotid Artery Disease. For the North American Symptomatic Carotid Endarterectomy (NASCET) Group. Stroke, 31, 631-636. http://dx.doi.org/10.1161/01.STR.31.3.631

[17] Caplan, L.R. (1989) Intracranial Branch Atheromatous Disease A Neglected, Understudied, and Underused Concept. Neurology, 39, 1246-1246. http://www.neurology.org/content/39/9/1246.

[18] Derdeyn, C.P., Grubb, R.L. and Powers, W.J. (1999) Cerebral Hemodynamic Impairment, Methods of Measurement and Association with Stroke Risk. Neurology, 53, 251-251. http://www.neurology.org/content/53/2/251.

[19] Yamauchi, H., Nishii, R., Higashi, T., Kagawa, S. and Fukuyama, H. (2009) Hemodynamic Compromise as a Cause of Internal Border-Zone Infarction and Cortical Neuronal Damage in Atherosclerotic Middle Cerebral Artery Disease. Stroke, 40, 3730-3735. http://dx.doi.org/10.1161/STROKEAHA.109.560011

[20] Naritomi, H., Sawada, T., Kuriyama, Y., Kinugawa, H., Kaneko, T. and Takamiya, M. (1985) Effect of Chronic Middle Cerebral Artery Stenosis on the Local Cerebral Hemodynamics. Stroke, 16, 214-219. http://dx.doi.org/10.1161/01.STR.16.2.214

[21] Kim, Y.D., Cha, M.J., Kim, J., Lee, D.H., Lee, H.S., Nam, C.M., et al. (2011) Increases in Cerebral Atherosclerosis According to $\mathrm{CHADS}_{2}$ Scores in Patients with Stroke with Nonvalvular Atrial Fibrillation. Stroke, 42, 930-934. http://dx.doi.org/10.1161/STROKEAHA.110.602987 
[22] Lee, D.K., Kim, J.S., Kwon, S.U., Yoo, S.H. and Kang, D.W. (2005) Lesion Patterns and Stroke Mechanism in Atherosclerotic Middle Cerebral Artery Disease: Early Diffusion-Weighted Imaging Study. Stroke, 36, 2583-2588. http://dx.doi.org/10.1161/01.STR.0000189999.19948.14

[23] Pico, F., Labreuche, J., Cohen, A., Touboul, P.J. and Amarenco, P. (2004) Intracranial Arterial Dolichoectasia Is Associated with Enlarged Descending Thoracic Aorta. Neurology, 63, 2016-2021. http://dx.doi.org/10.1212/01.WNL.0000145845.12577.0F

[24] Smoker, W.R., Price, M.J., Keyes, W.D., Corbett, J.J. and Gentry, L.R. (1986) High-Resolution Computed Tomography of the Basilar Artery: 1. Normal Size and Position. American Journal of Neuroradiology, 7, 55-60.

[25] Hennerici, M., Rautenberg, W., Sitzer, G. and Schwartz, A. (1987) Transcranial Doppler Ultrasound for the Assessment of Intracranial Arterial Flow Velocity-Part 1. Examination Technique and Normal Values. Surgical Neurology, 27, 439-448. http://dx.doi.org/10.1016/0090-3019(87)90251-5

[26] Caplan, L.R. (2005) Dilatative Arteriopathy (Dolichoectasia): What Is Known and Not Known. Annals of Neurology, 57, 469-471. http://dx.doi.org/10.1002/ana.20447

[27] He, J., Whelton, P.K., Vu, B. and Klag, M.J. (1998) Aspirin and Risk of Hemorrhagic Stroke: A Meta-Analysis of Randomized Controlled Trials. JAMA, 280, 1930-1935. http://dx.doi.org/10.1001/jama.280.22.1930

[28] Alazzaz, A., Thornton, J., Aletich, V.A., Debrun, G.M., Ausman, J.I. and Charbel, F. (2000) Intracranial Percutaneous Transluminal Angioplasty for Arteriosclerotic Stenosis. Archives of Neurology, 57, 1625-1630. http://archneur.ama-assn.org/cgi/content/abstract/57/11/1625

[29] Connors 3rd, J.J. and Wojak, J.C. (1999) Percutaneous Transluminal Angioplasty for Intracranial Atherosclerotic Lesions: Evolution of Technique and Short-Term Results. Journal of Neurosurgery, 91, 415-423. http://www.ncbi.nlm.nih.gov/pubmed/10470816

[30] Fiorella, D., Masaryk, T.J. and Turk, A.S. (2010) Technical Aspects of Intracranial Angioplasty and Stenting. Cerebral Revascularization: Microsurgical and Endovascular Techniques.

[31] Yu, S.C., Leung, T.W., Hung, E.H., Lee, K.T. and Wong, L.K. (2012) Angioplasty and Stenting for Intracranial Atherosclerotic Stenosis with Nitinol Stent: Factors Affecting Technical Success and Patient Safety. Neurosurgery, 70, ons104-ons113.http://dx.doi.org/10.1227/NEU.0b013e3182320bb0

[32] Zhao, Z.W., Deng, J.P., He, S.M., Qin, H.Z., Gao, L. and Gao, G.D. (2009) Intracranial Angioplasty with GatewayWingspan System for Symptomatic Atherosclerotic Stenosis: Preliminary Results of 27 Chinese Patients. Surgical Neurology, 72, 607-611. http://dx.doi.org/10.1016/j.surneu.2009.06.017

[33] Sundt Jr., T.M., Smith, H.C., Campbell, J.K., Vlietstra, R.E., Cucchiara, R.F., Stanson, A.W. (1980) Transluminal Angioplasty for Basilar Artery Stenosis. Mayo Clinic Proceedings, 55, 673-680.

[34] Callahan 3rd, A.S. and Berger, B.L. (1997) Balloon Angioplasty of Intracranial Arteries for Stroke Prevention. Journal of Neuroimaging, 7, 232-235.

[35] Marks, M.P., Marcellus, M., Norbash, A.M., Steinberg, G.K., Tong, D. and Albers, G.W. (1999) Outcome of Angioplasty for Atherosclerotic Intracranial Stenosis. Stroke, 30, 1065-1069. http://stroke.ahajournals.org/content/30/5/1065

[36] Connors 3rd, J.J. and Wojak, J.C. (1999) Percutaneous Transluminal Angioplasty for Intracranial Atherosclerotic Lesions: Evolution of Technique and Short-Term Results. Journal of Neurosurgery, 91, 415-423. http://dx.doi.org/10.3171/jns.1999.91.3.0415

[37] Nahser, H.C., Henkes, H., Weber, W., Berg-Dammer, E., Yousry, T.A. and Kühne, D. (2000) Intracranial Vertebrobasilar Stenosis: Angioplasty and Follow-Up. American Journal of Neuroradiology, 21, 1293-1301.

[38] Marks, M.P., Marcellus, M.L., Do, H.M., Schraedley-Desmond, P.K., Steinberg, G.K., Tong, D.C., et al. (2005) Intracranial Angioplasty without Stenting for Symptomatic Atherosclerotic Stenosis: Long-Term Follow-Up. American Journal of Neuroradiology, 26, 525-530. http://www.ajnr.org/content/26/3/525

[39] Qureshi, A.I. (2012) Interpretation and Implications of the Prematurely Terminated Stenting and Aggressive Medical Management for Preventing Recurrent Stroke in the Intracranial Stenosis (SAMMPRIS) Trial. Neurosurgery, 70, E264-E268. http://dx.doi.org/10.1227/NEU.0b013e318239f318

[40] Tarr, R.W., Albuquerque, F., Hirsh, J. and Prestigiacomo, C. (2011) The SAMMPRIS Trial: The End or Just the Beginning. Journal of Neurointerventional Surgery, 3, 310-311. http://dx.doi.org/10.1136/neurintsurg-2011-010144

[41] Mori, T., et al. (1997) Percutaneous Transluminal Cerebral Angioplasty: Serial Angiographic Follow-Up after Successful Dilatation. Neuroradiology, 39, 111-116.

[42] Powers, W.J., Clarke, W.R., Grubb Jr., R.L., Videen, T.O., Adams Jr., H.P., Derdeyn, C.P. (2011) Extracranial-Intracranial Bypass Surgery for Stroke Prevention in Hemodynamic Cerebral Ischemia: The Carotid Occlusion Surgery Study Randomized Trial. JAMA, 306, 1983-1992. http://dx.doi.org/10.1001/jama.2011.1610

[43] Platform, I.C.T.R. (2012) Early Stent-Assisted Angioplasty in Symptomatic Intracranial Stenosis (ESASIS). 
[44] Derdeyn, C.P., Videen, T.O., Simmons, N.R., Yundt, K.D., Fritsch, S.M., Grubb Jr., R.L., et al. (1999) Count-Based PET Method for Predicting Ischemic Stroke in Patients with Symptomatic Carotid Arterial Occlusion. Radiology, 212, 499-506.

[45] Dorros, G., Cohn, J.M. and Palmer, L.E. (1998) Stent Deployment Resolves a Petrous Carotid Artery Angioplasty Dissection. American Journal of Neuroradiology, 19, 392-394.

[46] Phatouros, C.C., Higashida, R.T., Malek, A.M., Smith, W.S., Mully, T.W., DeArmond, S.J., et al. (1999) Endovascular Stenting of an Acutely Thrombosed Basilar Artery: Technical Case Report and Review of the Literature. Neurosurgery, 44, 667-673. http://dx.doi.org/10.1097/00006123-199903000-00134

[47] Morris, P.P., Martin, E.M., Regan, J. and Braden, G. (1999) Intracranial Deployment of Coronary Stents for Symptomatic Atherosclerotic Disease. American Journal of Neuroradiology, 20, 1688-1694.

[48] Yu, W., Smith, W.S., Singh, V., Ko, N.U., Cullen, S.P. and Dowd, C.F. (2005) Long-Term Outcome of Endovascular Stenting for Symptomatic Basilar Artery Stenosis. Neurology, 64, 1055-1057. http://www.neurology.org/content/64/6/1055

[49] Gomez, C.R., Misra, V.K., Liu, M.W., Wadlington, V.R., Terry, J.B. and Tulyapronchote, R. (2000) Elective Stenting of Symptomatic Basilar Artery Stenosis. Stroke, 31, 95-99. http://stroke.ahajournals.org/content/31/1/95

[50] Mazighi, M., Yadav, J.S. and Abou-Chebl, A. (2008) Durability of Endovascular Therapy for Symptomatic Intracranial Atherosclerosis. Stroke, 39, 1766-1769. http://dx.doi.org/10.1161/STROKEAHA.107.500587

[51] SSYLVIA Study Investigators (2004) Stenting of Symptomatic Atherosclerotic Lesions in the Vertebral or Intracranial Arteries (SSYLVIA) Study Results. Stroke, 35, 1388-1392. http://dx.doi.org/10.1161/01.STR.0000128708.86762.d6

[52] Lutsep, H.L. (2009) Symptomatic Intracranial Stenosis: Best Medical Treatment vs. Intracranial Stenting. Current Opinion in Neurology, 22, 69-74. http://dx.doi.org/10.1097/WCO.0b013e32831504e4

[53] Steinfort, B., Ng, P.P., Faulder, K., Harrington, T., Grinnell, V., Sorby, W., et al. (2007) Midterm Outcomes of Paclitaxel-Eluting Stents for the Treatment of Intracranial Posterior Circulation Stenoses. Journal of Neurosurgery, 106, 222225. http://dx.doi.org/10.3171/jns.2007.106.2.222

[54] Qureshi, A.I., Kirmani, J.F., Hussein, H.M., Harris-Lane, P., Divani, A.A., Suri, M.F., et al. (2006) Early and Intermediate-Term Outcomes with Drug-Eluting Stents in High-Risk Patients with Symptomatic Intracranial Stenosis. Neurosurgery, 59, 1044-1051.

[55] Abou-Chebl, A., Bashir, Q. and Yadav, J.S. (2005) Drug-Eluting Stents for the Treatment of Intracranial Atherosclerosis: Initial Experience and Midterm Angiographic Follow-Up. Stroke, 36, e165-e168. http://dx.doi.org/10.1161/01.STR.0000190893.74268.fd

[56] Gupta, R., Al-Ali, F., Thomas, A.J., Horowitz, M.B., Barrow, T., Vora, N.A., et al. (2006) Safety, Feasibility, and Short-Term Follow-Up of Drug-Eluting Stent Placement in the Intracranial and Extracranial Circulation. Stroke, 37, 2562-2566. http://dx.doi.org/10.1161/01.STR.0000242481.38262.7b

[57] Natarajan, S.K., Ogilvy, C.S., Hopkins, L.N., Siddiqui, A.H. and Levy, E.I. (2010) Initial Experience with an Everolimus-Eluting, Second-Generation Drug-Eluting Stent for Treatment of Intracranial Atherosclerosis. Journal of NeuroInterventional Surgery, 2, 104-109. http://dx.doi.org/10.1136/jnis.2009.001875

[58] Rahme, R.J., Aoun, S.G., Batjer, H.H. and Bendok, B.R. (2011) SAMMPRIS: End of Intracranial Stenting for Atherosclerosis or Back to the Drawing Board? Neurosurgery, 69, N16-N18. http://dx.doi.org/10.1227/01.neu.0000407920.96189.cc

[59] Benesch, C.G. and Chimowitz, M.I. (2000) Best Treatment for Intracranial Arterial Stenosis? Neurology, 55, $465-466$. http://dx.doi.org/10.1212/WNL.55.4.465

[60] Fiorella, D.J., Turk, A.S., Levy, E.I., Pride Jr., G.L., Woo, H.H., Albuquerque, F.C., et al. (2011) US Wingspan Registry. Stroke, 42, 1976-1981. http://dx.doi.org/10.1161/STROKEAHA.111.613877

[61] Jiang, W.J., Cheng-Ching, E., Abou-Chebl, A., Zaidat, O.O., Jovin, T.G., Kalia, J., et al. (2012) Multicenter Analysis of Stenting in Symptomatic Intracranial Atherosclerosis. Neurosurgery, 70, 25-31. http://dx.doi.org/10.1227/NEU.0b013e31822d274d

[62] Higashida, R.T., Tsai, F.Y., Halbach, V.V., Dowd, C.F., Smith, T., Fraser, K., et al. (1993) Transluminal Angioplasty for Atherosclerotic Disease of the Vertebral and Basilar Arteries. Journal of Neurosurgery, 78, 192-198. http://dx.doi.org/10.3171/jns.1993.78.2.0192

[63] Terada, T., Higashida, R.T., Halbach, V.V., Dowd, C.F., Nakai, E., Yokote, H., et al. (1996) Transluminal Angioplasty for Arteriosclerotic Disease of the Distal Vertebral and Basilar Arteries. Journal of Neurology, Neurosurgery \& Psychiatry, 60, 377-381. http://dx.doi.org/10.1136/jnnp.60.4.377

[64] Takis, C., Kwan, E.S., Pessin, M.S., Jacobs, D.H. and Caplan, L.R. (1997) Intracranial Angioplasty: Experience and Complications. American Journal of Neuroradiology, 18, 1661-1668. 
[65] Grubb, R.L., Derdeyn, C.P., Fritsch, S.M., Carpenter, D.A., Yundt, K.D., Videen, T.O., et al. (1998) Importance of Hemodynamic Factors in the Prognosis of Symptomatic Carotid Occlusion. JAMA: The Journal of the American Medical Association, 280, 1055-1060. http://dx.doi.org/10.1001/jama.280.12.1055

[66] Carlson, A.P., Yonas, H., Chang, Y.F. and Nemoto, E.M. (2011) Failure of Cerebral Hemodynamic Selection in General or of Specific Positron Emission Tomography Methodology? Carotid Occlusion Surgery Study (COSS). Stroke, 42, 3637-3639. http://dx.doi.org/10.1161/STROKEAHA.111.627745

[67] (1985) Failure of Extracranial-Intracranial Arterial Bypass to Reduce the Risk of Ischemic Stroke. Results of an International Randomized Trial. The EC/IC Bypass Study Group. The New England Journal of Medicine, 313, 1191-200. http://dx.doi.org/10.1056/NEJM198511073131904

[68] Powers, W.J. (2012) Letter by Powers Regarding Article, "Failure of Cerebral Hemodynamic Selection in General or of Specific Positron Emission Tomography Methodology? Carotid Occlusion Surgery Study (COSS)”. Stroke, 43, e43. http://dx.doi.org/10.1161/STROKEAHA.111.648097 